\title{
SISTEM INFORMASI PEMASARAN PRODUK KOPI TRABAS ARGAMAKMUR BERBASIS WEBSITE
}

\author{
${ }^{1}$ Kirman, ${ }^{2}$ Ade Anugrah Hanafiah \\ ${ }^{1.2}$ Program Studi Sistem Informasi Fakultas Teknik \\ e-mail:1 kirman@umb.ac.id, 2adeanugrahhanafiah@gmail.com
}

\begin{abstract}
ABSRACT - Kopi Trabas is an store that provides gadgets which requires an expansion on sales and promotion of its products for customer inside and outside Bengkulu. Kopi Trabasis still using Banner for its promotion and the recording transaction are still manual so it is likely to make a mistake and a data loss. At the time, the way of purchase at Kopi Trabas are the customer directly came into the store to see and ordering products that are provided by the store. By developing a web-based sales information system on the Kopi Trabas is, it would help the store and the customer on making transactions and helps the store to promote the store's products over the internet. The system is using DFD (Data Flow Diagram). The results of webbased sales information system research could be implemented and be a good use for the store on promoting its product and easily making transactions to the customers online.

Keywords: Web-based sales information systems, DFD (Data Flow Diagram).

ABSTRAK - Kopi Trabas merupakan toko yang bergerak di bidang penjualan kopi yang masih memerlukan adanya perluasan wilayah dalam penjualan dan pemasaran produk yang disediakan baik untuk pelanggan didalam kota Bengkulu maupun diluar Bengkulu. Untuk promosi produk yang dijual pada Kopi Trabas saat ini hanya dilakukan dengan menggunakan Banner dan pencatatan transaksi pada toko ini juga masih bersifat manual sehingga memungkinkan terjadinya kesalahan dalam pencatatan juga memungkinkan adanya kehilangan data. Pada saat ini cara pembelian pada toko Kopi Trabas adalah pelanggan secara langsung ke toko untuk melihat dan memesan produk yang disediakan. Dengan membangun sistem informasi penjualan berbasis webs pada Kopi Trabas maka dapat membantu toko dan pelanggan dalam melakukan transaksi jual beli, juga dapat membantu perusahaan mempromosikan produk melalui internet. Metode perancangan menggunakan pemodelan DFD (Data Flow Diagram). Hasil dari penelitian ini berupa perancangan sistem penjualan berbasis web yang dapat diimplementasikan dengan baik oleh pemilik guna mempromosikan produk dan melakukan transaksi jual beli secara mudah kepada pelanggan dan online.
\end{abstract}

\section{Kata Kunci: Sistem Penjualan berbasis web, DFD (Data Flow Diagram.}

\section{PENDAHULUAN}

Perkembangan item informai dalam bidang ilmu pengetahuan dan teknologi dalam beberapa tahun terakhir sangatlah pesat. Dengan berkembangnya teknologi, sistem telah dikembangkan dan dikombinasikan dengan berbagai aspek untuk membantu manusia dalam menyelesaikan pekerjaannya. Sistem informasi ialah serangkaian komponen berupa manusia, prosedur, data dan teknologi (seperti komputer) yang digunakan untuk melakukan sebuah proses untuk menghasilkan informasi yang bernilai dalam mengambil keputusan $^{1}$.

Sistem informasi yaitu kumpulan komponen yang saling terkait dan bekerja satu sama lain untuk mengumpulkan, memproses, menyimpan serta mendistribusikan informasi terkait dalam mendukung proses pengambilan keputusan, koordinasi dan pengendalian. Perkembangan teknologi informasi yang kian cepat dengan disertai perkembangan internet yang semakin luas banyak diterapkan dalam bidang bisnis di masa sekarang, dan dapat menjadi salah satu faktor pembantu untuk mempromosikan komoditas daerah, salah satunya adalah dalam bidang kopi.

Kota Bengkulu lebih tepatnya di kabupaten Bengkulu utara, kecamatan Padang jaya, desa
Tanah hitam merupakan daerah penghasil kopi, salah satu usaha rumahan yang ada di desa Tanah hitam yaitu kopi trabas. Kopi trabas merupakan tanaman kopi jenis robusta yang berasal dari kebun petani masyarakat setempat. Kopi di Indonesia sendiri memiliki sejarah yang panjang dan memiliki peranan penting bagi pertumbuhan perekonomian masyarakat di Indonesia. Indonesia memiliki letak geografis yang sangat cocok difungsikan sebagai lahan perkebunan kopi, letak Indonesia pun sangat ideal bagi iklim mikro untuk pertumbuhan dan produksi kopi ${ }^{2}$. Mengapa dalam hal ini tema kopi yang diangkat penulis, karena kebutuhan kopi yang cukup besar dan budaya ngopi yang saat ini sudah menjadi trend di kalangan muda.

Selain itu, kopi trabas masih menggunakan sistem penjualan yang tergolong konvensional. Hal ini membuat seringnya terjadi kesalahan informasi yang cukup besar. Konsumen hanya bisa membeli kopi trabas ketika mengunjungi rumah produksinya langsung. Sehingga membuat pemasarannya sedikit terbatas. Dalam era globalisasi pemasaran konvensional sangat tidak efisien dan efektif untuk digunakan, karena memiliki beberapa kekurangan seperti biaya promosi yang mahal atau terkendala antara ruang dan waktu dalam proses pemasaran ${ }^{3}$. Maka dari itu sistem sangat dibutuhkan untuk kopi 
trabas agar penjualannya menjadi efisien dan diharapkan dapat membantu pihak pemilik usaha dan petani kopi setempat dalam memperkenalkan komoditas unggulannya.

Maka dari itu penulis ingin membangun sebuah "Sistem Informasi Pemasaran Kopi Trabas Argamakmur Berbasis Website". Yang bertujuan untuk memudahkan orang-orang untuk lebih mengetahui semua informasi tentang kopi trabas dan nantinya konsumen dapat melihat dan membeli secara online melalui website yang akan dibuat tanpa harus datang ke lokasi produksinya lagi. Website adalah layanan yang menyediakan informasi secara update yang dapat diakses tanpa dibatasi oleh jarak dan waktu. Menurut ${ }^{4}$. Website adalah suatu halaman yang didalamnya memuat situs web page yang berada di internet yang berfungsi sebaga media penyampaian informasi, komunikasi, dan transaksi. Pembuatan website dipilih karena sudah saatnya industri kreatif rumahan seperti kopi trabas harus memiliki sistem penjualan mereka sendiri agar bisa di maintenance serta mengelola produk yang mereka jual.

\section{LANDASAN TEORI}

A. Pengertian Sistem

Sistem adalah kumpulan dari komponen atau elemen yang saling berhubungan satu dengan yang lainnya membentuk satu kesatuan untuk mencapai tujuan tertentu. Suatu sistem terdiri dari sekumpulan elemen-elemen. Elemen-elemen saling bekerja sama untuk mencapai tujuan sistem. Suatu elemen yang telah ada merupakan bagian dari sistem lain yang lebih besar ${ }^{5}$.

\section{B. Pengertian Informasi}

Informasi sebagai data yang telah diproses sedemikian rupa sehingga meningkatkan pengetahuan seseorang yang menggunakan data tersebut ${ }^{7}$.

\section{Pengertian Pemasaran}

Pemasaran adalah suatu proses sosial yang di dalamnya individu dan kelompok mendapatkan apa yang mereka butuhkan dan inginkan dengan menciptakan, menawarkan, dan secara bebas mempertukarkan produk yang bernilai dengan pihak lain ${ }^{7}$. Dari pendapat yang dikemukakan ini maka dapat disimpulkan bahwa pemasaran adalah sebagai proses sosial yang didalamnya terdapat individu/kelompok. Kegiatan yang terdapat didalamnya yaitu menciptakan, menawarkan dan mempertukarkan produk atau jasa yang bernilai.

\section{Pengertian Produk}

Menyebutkan produk adalah segala sesuatu yang dapat ditawarkan untuk memuaskan suatu kebutuhan dan keinginan ${ }^{5}$. Dari pendapat ini dapat disimpulkan bahwa produk adalah segala sesuatu yang ditawarkan, didistribusikan dan dimanfaatkan oleh konsumen guna memenuhi kebutuhannya.

\section{E. Pengertian Kopi Trabas}

Nama awalnya ialah Kopi Tanah Hitam Trabas. Tanaman kopi robusta biji petik merah ini berasal dari Desa Tanah hitam, Kecamatan Padang jaya, Kabupaten Bengkulu utara, Kota Argamakmur. Tanaman kopi ini berasal dari kebun petani masyarakat setempat yang memiliki cita rasa khas yang manis. Konon bibit kopi ini berasal dari Belanda ketika menjajah Bengkulu. Kopi Trabas menggunakan beberapa metode pengelolaan kopi agar menghasilkan cita rasa kopi yang tinggi.

Dimana biji kopi dipilih secara teliti dan dipetik yang merah. Lalu melewati proses full wash atau proses basah. Tahapan ini biji petik merah direndam dalam wadah atau bak yang bertujuan mengambil biji petik merah yang tenggelam, biji petik merah yang mengapung pun dipisahkan. Kemudian biji petik merah dicuci beberapa kali hingga lendirnya hilang dan bersih. Kemudian proses pengelolaan dilanjutkan dengan perendaman buah biji merah selama 24 jam lamanya. Setelah itu barulah dilakukan penjemuran di balai dump. Proses selanjutnya yaitu dinamakan honey process. Langkah ini biji kopi yang masih berlendir kembali dijemur hingga kelembaban $12 \%$. Setelah biji benarbenar kering maka proses akhir adalah natural process,yang mana biji petik merah yang telah kering kering akan ditumbuk dengan menggunakan mesin kopi.

\section{METODE PENELITIAN}

\section{A. Alur Penelitian}

Berdasarkan metode penelitian yang digunakan pada penelitian ini, dapat digunakan suatu alur kegiatan metode kerangka penelitian seperti terlihat pada gambar dibawah ini:

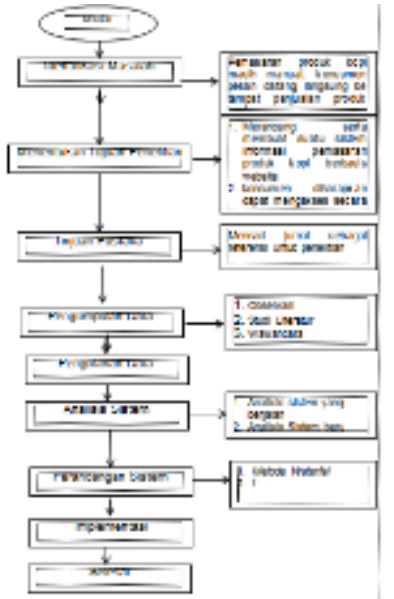

Gbr 1 Alur Penelitian

\section{B. Metode Waterfall}

Metode air terjun atau yang sering disebut metode waterfall sering dinamakan siklus hidup klasik (classic life cycle), dimana hal ini

7 |http://www.jurnal.umb.ac.id/index.php/JTIS 
menggambarkan pendekatan yang sistematis dan juga berurutan pada pengembangan perangkat lunak, dimulai dengan spesifikasi kebutuhan pengguna lalu berlanjut melalui tahapan-tahapan perencanaan (planning), permodelan (modeling), konstruksi (construction), serta penyerahan sistem ke para pelanggan/pengguna (deployment), yang diakhiri dengan dukungan pada perangkat lunak lengkap yang dihasilkan (Pressman, 2012). Tahapan metode waterfall dapat dilihat pada gambar di bawah ini.

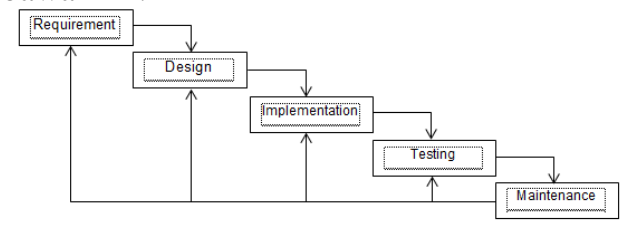

Gbr 2 Tahapan Metode Waterfall

\section{Data Flow Diagram(DFD)}

Adapun gambar Data Flow Diagram(DFD) yang pada Sistem informasi kopi Trabas yang digambarkan sebagai berikut:

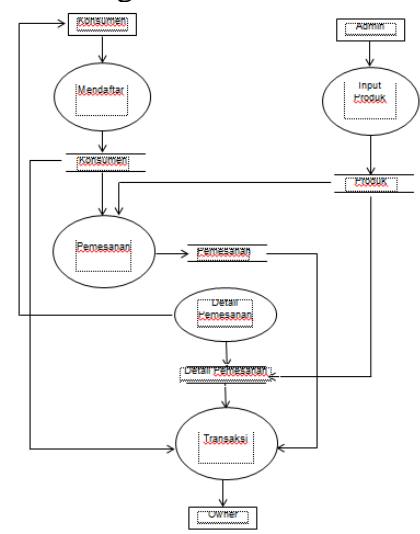

Gbr 3 Data Flow Diagram(DFD) level 0

D. Entity Relationship Diagram (ERD)

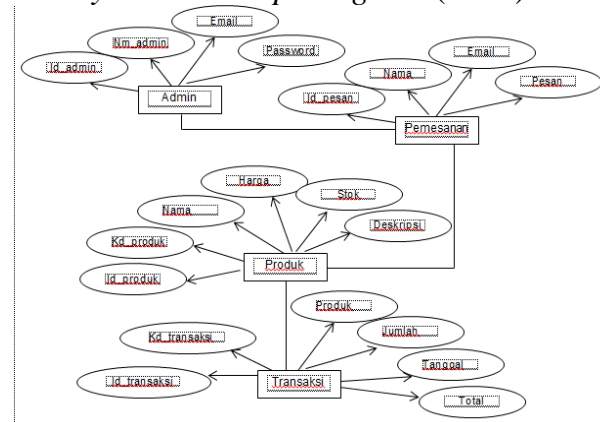

Gbr 4 Entity Relationship Diagram (ERD)

\section{IMPLEMENTASI DAN ANALISIS}

A. Hasil Implementasi

Hasil implementasi pada Sistem Informasi Pemasaran Produk Kopi Trabas Argamakmur Berbasis Website terdiri dari form-form sebagai berikut :

1. Tampilan Form Menu Utama
Login berhasil maka masuk ke menu home. Jika username adalah user maka hanya dapat mengakses transaksi pembelian. Tetapi jika username petugas gudang maka dapat membuka transaksi barang. Tampilan form setelah login atau form menu utama dapat dilihat pada Gambar 5

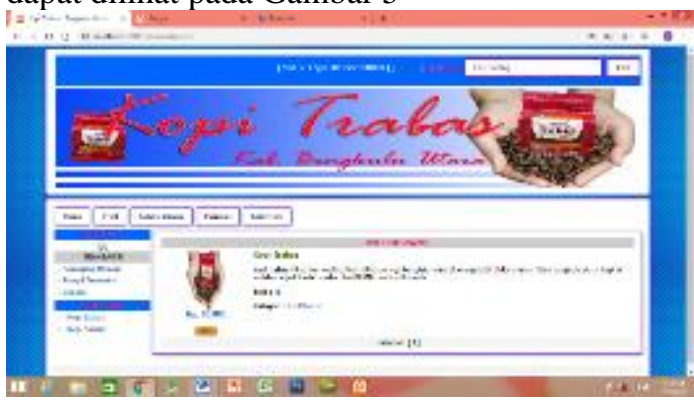

Gbr 5. Tampilan Form Menu Utama

2. Tampilan Form Keranjang Belanja

Gambar 6 di bawah adalah untuk memasukkan data barang yang diterima dari konsumen yang akan disimpan pada data barang. Menyediakan button simpan untuk menyimpan data barang baru. Button hapus berfungsi untuk menghapus data pembelian barang. Didalam tabel data barang juga terdapat link edit dan hapus.

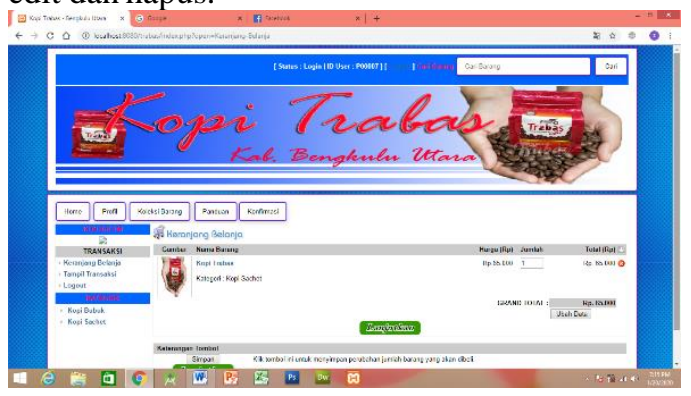

Gbr 6 Form Keranjang Belanja

3. Tampilan Form Konfirmasi Pesanan

Gambar 7 di bawah adalah untuk memasukkan data barang yang diterima dari supplier yang akan disimpan pada data store barang. Menyediakan button simpan untuk menyimpan data barang baru. Button reset berfungsi untuk mereset data barang. Didalam tabel data barang juga terdapat link edit dan hapus.

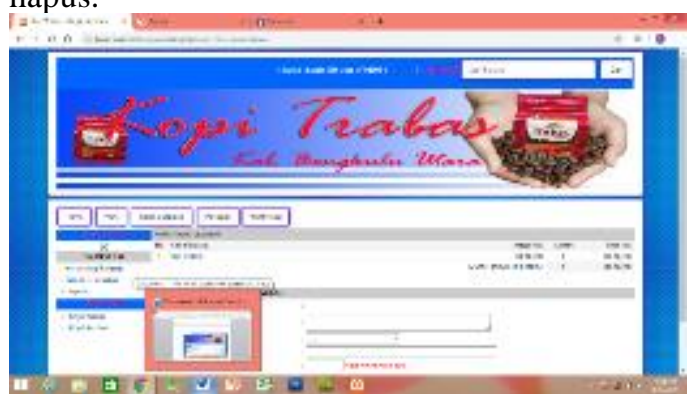

Gbr 7 Form Keranjang Belanja

4. Tampilan Form Cetak Pesanan

Gambar 8 di bawah adalah untuk memasukkan data barang yang diterima dari supplier yang akan 
disimpan pada data store barang. Menyediakan button simpan untuk menyimpan data barang baru. Button reset berfungsi untuk mereset data barang. Didalam tabel data barang juga terdapat link edit dan hapus.

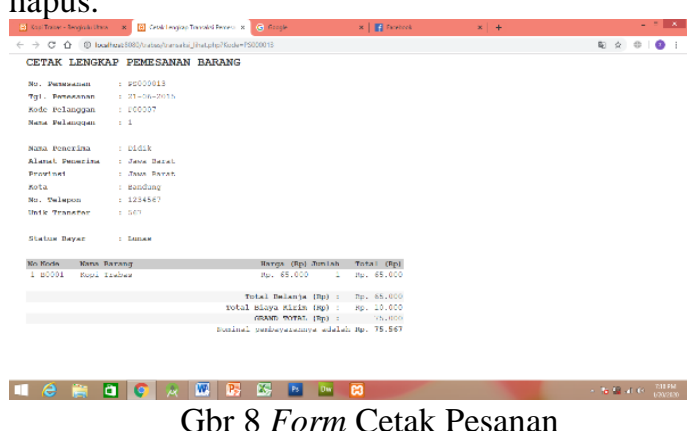

5. Tampilan Form Data Barang

Gambar 9 di bawah adalah untuk memasukkan data barang yang diterima dari supplier yang akan disimpan pada data store barang. Menyediakan button simpan untuk menyimpan data barang baru. Button reset berfungsi untuk mereset data barang. Didalam tabel data barang juga terdapat link edit dan hapus

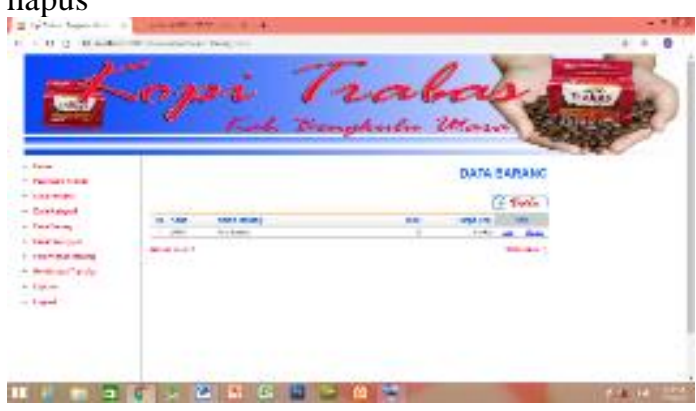

Gbr 9 Form Data Barang

6. Tampilan Form Input Data Barang Masuk

Gambar di bawah adalah tampilan setelah memilih link lihat supplier dan link lihat barang. Data barang akan tampil dan memasukkan stock barang datang serta menyediakan tanggal barang datang tersebut. Tampilan form input data barang masuk dapat dilihat pada Gambar 4.7

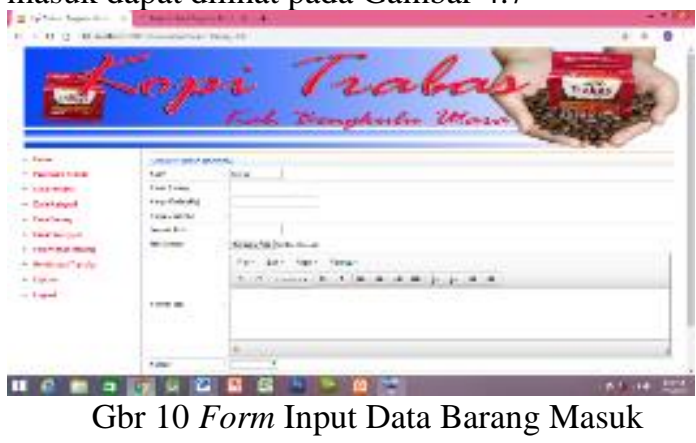

7. Tampilan Form Laporan Data Barang

Form dibawah adalah tampilan form laporan data barang. Menyediakan informasi data barang masuk dan keluar serta data stock barang yang masih ada. Tampilan form laporan data barang dapat dilihat pada Gambar 11

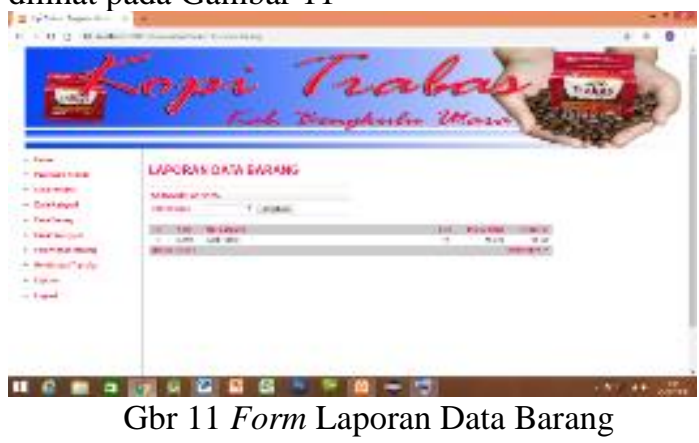

\section{Tampilan Form Laporan Pemesanan Barang}

Form dibawah ini adalah tampilan laporan pemesanan barang secara tahunan. Pada form ini juga menyediakan laporan harian dan bulanan. Serta menyediakan laporan laba ruginya. Tampilan form laporan penjualan barang dapat dilihat pada Gambar 12

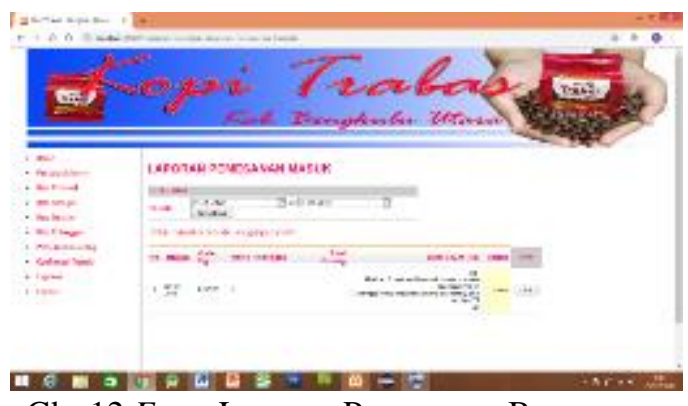

Gbr 12 Form Laporan Pemesanan Barang.

9. Tampilan Form Laporan Pembelian Barang

Gambar 13 adalah tampilan form laporan pembelian barang secara tahunan. Tidak hanya menyediakan laporan tahunan, namun juga pembelian barang secara harian dan bulanan.

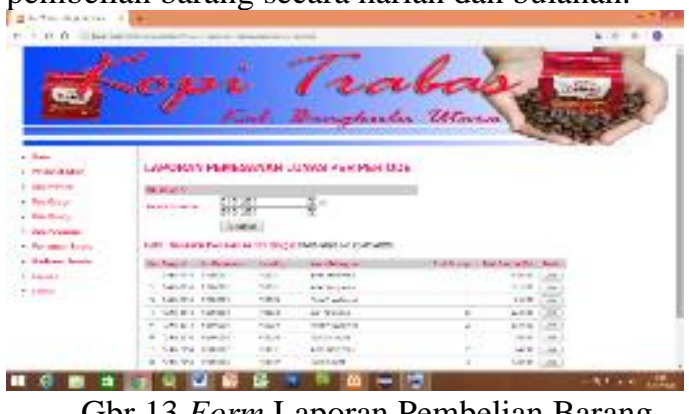

Gbr 13 Form Laporan Pembelian Barang

\section{PENUTUP}

\section{A. Kesimpulan}

Kesimpulan yang dihasilkan dari serangkaian pembahasan dan pengujian Sistem Informasi Pemasaran Produk Kopi Trabas Argamakmur Berbasis Website di atas ini dapat disimpulkan sebagai berikut:

1. Telah dibuat Sistem Informasi Pemasaran Produk Kopi Trabas Argamakmur Berbasis Website mempunyai fasilitas data stok barang,

9 |http://www.jurnal.umb.ac.id/index.php/JTIS 
data transaksi penjualan, pembelian, dan laporan. Sehingga sistem dapat membantu proses penjualan barang.

2. Sistem Informasi Pemasaran Produk Kopi Trabas Argamakmur Berbasis Website ini menggunakan software macromedia dreamweaver dan database MySQL ( Xampp ).

3. Dengan adanya sistem informasi ini, konsumen lebih memilih untuk melakukan pembelian melalui Websitesite daripada membeli dengan datang langsung ke tempat pembelian produk kopi.

4. Manfaat dari pembuatan Sistem Penjualan Biji Kopi Berbasis Website ini adalah untuk menarik minat konsumen untuk mengetahui informasi produk kopi yang ada pada sistem informasi ini. Sebelumnya konsumen diharuskan datang langsung ke tempat jika ingin membeli produk kopi tanpa mengetahui informasi produk kopi, stok kopi yang masih tersedia.

B. Saran

Mengingat pembuatan Sistem Informasi Pemasaran Produk Kopi Trabas Argamakmur Berbasis Website masih memiliki kelemahan, yaitu

1. Belum dilengkapi dengan tanggal expired. Diharapkan ada pihak-pihak tertentu yang mengembangkannya sehingga jika masa expired sudah terlampaui maka stok barang expired hilang.

2. Jika sistem informasi penjualan biji kopi ini berkembang dengan baik, penulis menyarankan untuk dikembangkannya fitur pembayaran melalui sistem informasi penjualan produk kopi ini.

\section{Referensi}

[1] Soeherman. Bonnie, Pinontoan 2008, Designing Information system

[2] Widiyanto, 2012, Sistem Pakar Identifikasi Pengecekan Kualitas Kopi Berbasis Web Dengan Mengunakan Metode Certainty Factor, Vol.5, No.3

[3] Salehi, M., M. Hanieh, A. Mohammadreza, and A. Milad. 2012. Dissimilarity of E-marketing vs traditional marketing. International Journal of Academic Research in Business and Social Sciences, 2(1): 510-515

[4] Hastanti, dkk, 2015, Sistem Penjualan Bebasis Web(Ecommerce) Pada Tata Distro Kabupaten Pacitan. Jurnal Bianglala Informatika, 3(2), 1-9

[5] Jogiyanto, H.M 2005, Analisis Dan Desain Sistem Informasi : pendekatan terstruktur teori dan praktek aplikasi bisnis. Yogyakarta: Andi Offset

[6] Kotler (2005) Manajemen Pemasaran Jilid 1 dan 2, Jakarta: PT Indeks Kelompok Gramedia

[7] Abdul Kadir (2002:31), Mc Fadden $\operatorname{dkk}(1999)$ Pemrograman Database Menggunakan Delphi 7.0 Menggunakan Acces ADO, Andi, Yogyakarta

[8] Kotler dan Keller, 2007. Marketing Management. Global Edition. New Jersey: Pearson Education 